\title{
Color Stability of Restorative Resins Under Accelerated Aging*
}

\author{
JOHN M. POWERS, JOSEPH B. DENNISON, and ANDREW KORAN
}

\section{School of Dentistry, The University of Michigan, Ann Arbor, Michigan 48109}

The color stability of seven commercial composite resins, an unfilled resin, and three glazes was studied under conditions of accelerated aging by reflection spectrophotometry and visually with Munsell color tabs. After aging for 900 hours, most of the resins had lower values of luminous reflectance and excitation purity and higher values of dominant wavelength and contrast ratio compared to values at baseline.

J Dent Res 57(11-12):964-970, Nov.-Dec. 1978

\section{Introduction.}

Tooth-colored restorative resins have characteristically been unable to retain the shade developed at the time of insertion., Stain accumulation, dehydration, water sorption, and the chemical breakdown of unreacted components are factors contributing to color instability. Studies have been con ducted to simulate clinical stain accumulation using organic dyes and foodstuffs $3^{3,4}$ and have related discoloration to surface texture and finishing technique. Resin materials accelerated by ultraviolet (uv) radiation have been shown to be less color stable than amine-accelerated systems during the early period after polymerization. ${ }^{5}$ The American Dental Association Specification No. 27 for Direct Filling Resins includes a test for color stability in which one-half of a disk is exposed to radiation from a light source (S-1 bulb) in a dry environment and com-

Received for publication October 25, 1977

Accepted for publication April 18,1978

* This investigation was supported in part by Research Grant DE-04136 and by Biomedical Research Support Grant RR 05321 from the National Institute of Dental Research, National Institutes of Health, Bethesda, MD 20014.

This investigation was presented in part at the annual meeting of the American Association for Dental Research in Las Vegas, Nevada, June, 1977.

The cooperation of the following companies in providing commercial products is acknowledged: L. D. Caulk Co., Johnson \& Johnson, Kerr Manufacturing Co., Lee Pharmaceuticals, and $3 \mathrm{M} \mathrm{Co}$. pared to the unexposed half for visually perceptible color change. ${ }^{6}$ It is the intent of this study to simulate clinical shade deterioration using controlled weathering conditions and monitor color changes with frequent visual and spectrophotometric evaluations.

\section{Materials and methods.}

The color of seven commercial composite resins, three glazes, and an unfilled restorative resin was evaluated under conditions of accelerated aging. The code, shade, batch number, and manufacturer are listed in Table 1 for each material studied.

Five disks (36 $\mathrm{mm}$ in diameter and 1.3 $\mathrm{mm}$ in thickness) were prepared for each material according to conditions specified in a previous study. ${ }^{7}$ All samples were exposed to conditions of accelerated aging for a total of 900 hours in a weathering chamber ${ }^{*}$ at $43^{\circ} \mathrm{C}$ and 90 percent relative humidity. One surface of each sample was subjected continuously to the radiation of a 2500 watt xenon light sourcet with an intermittent water spray for 18 minutes every 102 minutes. Color evaluations were made before weathering (baseline) and after exposure of $10,20,50,100,300$, and 900 hours.

Munsell value, chroma, and hue were determined by two evaluators making visual comparisons with color tabs (glossy finish) for each resin at each time. Color difference (I) between each observation and the concensus color or between concensus colors at baseline and a subsequent time was

* Weather-Ometer 25-WR, Atlas Electric Devices Co., Chicago, Illinois 60613 .

$\uparrow 12-2881$ Xenon Burner, Atlas Electric Devices Co., Chicago, Illinois 60613 .

+ Munsell Book of Color, Munsell Color, Baltimore, Maryland 21218. 
TABLE 1

CODE, PRODUCT NAME AND SHADE, BATCH NUMBERS, AND MANUFACTURERS OF COMPOSITE AND UNFILLED RESINS AND GLAZES.

\begin{tabular}{|c|c|c|c|}
\hline Code & $\begin{array}{l}\text { Product name } \\
\text { (shade) }\end{array}$ & $\begin{array}{l}\text { Batch } \\
\text { numbers }\end{array}$ & Manufacturer \\
\hline \multicolumn{4}{|c|}{ Composite resins: } \\
\hline A & $\begin{array}{l}\text { Adaptic } \\
\text { (Universal) }\end{array}$ & $\begin{array}{l}\text { base }- \text { SF } 101 \\
\text { catalyst }- \text { SF101 }\end{array}$ & $\begin{array}{l}\text { Johnson \& Johnson } \\
\text { Dental Products Division } \\
\text { East Windsor, NJ 08520 }\end{array}$ \\
\hline AR & $\begin{array}{l}\text { Adaptic Radi- } \\
\text { opaque (Universal) }\end{array}$ & $\begin{array}{l}\text { base }-1126 \mathrm{D} 03 \\
\text { catalyst }-1126 \mathrm{D} 03\end{array}$ & Johnson \& Johnson \\
\hline $\mathrm{C}$ & $\begin{array}{l}\text { Concise } \\
\text { (Universal) }\end{array}$ & $\begin{array}{l}\text { base }-6159 L 13 \\
\text { catalyst }-6159 L 13\end{array}$ & $\begin{array}{l}\text { 3M Company } \\
\text { St. Paul, MN } 55101\end{array}$ \\
\hline NF & $\begin{array}{l}\text { Nuva Fil } \\
\text { (Light) }\end{array}$ & $\begin{array}{l}\text { base }-7414,7426 \\
\text { initiator }-7661\end{array}$ & $\begin{array}{l}\text { L. D. Caulk Co. } \\
\text { Div. of Dentsply Inter- } \\
\text { national, Inc. } \\
\text { Milford, DE } 19963\end{array}$ \\
\hline $\mathrm{P}$ & $\begin{array}{l}\text { Prestige } \\
\text { (Universal) }\end{array}$ & $\begin{array}{l}\text { base - HPR0114 } \\
\text { catalyst - HPR0115 }\end{array}$ & $\begin{array}{l}\text { Lee Pharmaceuticals } \\
\text { South El Monte, CA } 91733\end{array}$ \\
\hline $\mathrm{S}$ & $\begin{array}{l}\text { Simulate } \\
\text { (Universal) }\end{array}$ & $\begin{array}{l}\text { base }-1066 \\
\text { catalyst }-1160\end{array}$ & $\begin{array}{l}\text { Kerr Manufacturing Co. } \\
\text { Div. of Sybron Corp. } \\
\text { Romulus, MI } 48174\end{array}$ \\
\hline V & $\begin{array}{l}\text { Vytol } \\
\text { (Light) }\end{array}$ & $\begin{array}{l}\text { base }-042976 \\
\text { catalyst }-042976\end{array}$ & L. D. Caulk Co. \\
\hline \multicolumn{4}{|c|}{ Unfilled resin: } \\
\hline SV & $\begin{array}{l}\text { Sevriton (Ss- } \\
\text { Light Yellow) }\end{array}$ & $\begin{array}{l}\text { powder - PA14PE } \\
\text { liquid - PH6PK }\end{array}$ & $\begin{array}{l}\text { Amalgamated Dental } \\
\text { Trade Dist., Ltd. } \\
\text { London, England }\end{array}$ \\
\hline \multicolumn{4}{|l|}{ Glazes: } \\
\hline F & Finite & $\begin{array}{l}\text { base }-041076 \\
\text { catalyst }- \text { G0025 }\end{array}$ & Lee Pharmaceuticals \\
\hline G & Adaptic Glaze & $\begin{array}{l}\text { base }-0815 \mathrm{D} 04 \\
\text { catalyst }-0815 \mathrm{D} 04\end{array}$ & Johnson \& Johnson \\
\hline NS & Nuva Seal & $\begin{array}{l}\text { base }-75104 \\
\text { initiator }-7661\end{array}$ & L. D. Caulk Co. \\
\hline
\end{tabular}

determined by the equation 8 , $\mathrm{I}=(\mathrm{C} / 5)$ $(2 \Delta \mathrm{H})+6 \Delta \mathrm{V}+3 \triangle \mathrm{C}$, where $\mathrm{C}$ is the average chroma and $\Delta \mathrm{H}, \Delta \mathrm{V}$ and $\Delta \mathrm{C}$ are the positive differences in hue, value, and chroma, respectively.

Curves of percent reflectance versus wavelength $(\lambda)$ were obtained for five samples of each resin between 405 and $700 \mathrm{~nm}$ with a double-beam, ultraviolet-visible spectrophotometer $\S$ and integrating sphere.

\& ACTA C III UV-Visible Spectrophotometer, Beckman Instruments, Inc., Irvine, California 92664.

I ASPH-U Integrating Sphere, Beckman Instruments, Inc., Irvine, California 92664.
Luminous reflectance (Y), dominant wavelength (DW), and excitation purity (EP) were obtained for each sample backed by both a black ${ }^{\infty}$ and a white** standard. ${ }^{7}$ An estimate of the opacity of each resin was obtained by calculation of the contrast ratio (CR), ${ }^{9} \mathrm{Y}$ black standard/Y white standard.

The spectrophotometric parameters ( $Y$, DW and EP) were studied by a two-way

$\infty$ Part No. 375287, Beckman Instruments, Inc., Irvine, California 92664.

**Part No. 104384, Beckman Instruments, Inc., Irvine, California 92664. 
TABLE 2

SPECTROPHOTOMETRIC AND MUNSELL COLOR DATA FOR COMPOSITE RESINS AT BASELINE AND AFTER AGING

\begin{tabular}{|c|c|c|c|c|c|c|c|c|c|c|c|c|c|c|}
\hline \multirow{3}{*}{$\frac{\text { Code }}{A}$} & \multirow{3}{*}{ Property* } & \multicolumn{13}{|c|}{ Time, hours } \\
\hline & & \multicolumn{2}{|r|}{0} & \multicolumn{2}{|c|}{10} & \multicolumn{2}{|c|}{20} & \multicolumn{2}{|c|}{50} & \multicolumn{2}{|c|}{100} & \multicolumn{2}{|c|}{300} & 900 \\
\hline & & & & & & & & & & & & & & \\
\hline & $\mathrm{Y}$ & 59.4 & $(1.3)$ & 57.8 & $(0.7)$ & 58.6 & $(0.9)$ & 58.9 & $(0.8)$ & 59.1 & $(0.6$ & 58.3 & (1.3 & 62.8 \\
\hline & DW & 578.90 & $(0.07)$ & 580.39 & $(0.18)$ & 580.18 & $(0.18)$ & 579.81 & $(0.07)$ & 579.72 & $(0.15)$ & 578.96 & $(0.13)$ & $579.50 \quad(0.11)$ \\
\hline & EP & 0.270 & $(0.004)$ & 0.222 & $(0.008)$ & 0.212 & $(0.010)$ & 0.215 & $5(0.012)$ & 0.220 & $(0.012)$ & 0.252 & $2(0.020)$ & $0.182(0.025)$ \\
\hline & CR & 0.675 & $5(0.012)$ & 0.698 & $3(0.021)$ & 0.703 & $(0.018)$ & 0.70 & $7(0.020)$ & 0.709 & $(0.026)$ & 0.730 & $0(0.035)$ & $0.827(0.025)$ \\
\hline \multicolumn{2}{|c|}{ Hue Value/Chroma } & $2.5 \mathrm{Y}$ & $7.5 / 3$ & $10 Y R$ & $7.5 / 2$ & $10 \mathrm{YP}$ & $7.5 / 2$ & $10 \mathrm{YF}$ & R $7.5 / 3$ & IOYR & $7.5 / 2$ & $2.5 Y$ & $7.5 / 3$ & l0YR $7.5 / 2$ \\
\hline \multicolumn{15}{|l|}{$\mathrm{AR}$} \\
\hline & Y & 61.0 & $(1.0)$ & 58.2 & $(1.0)$ & 58.1 & $(1.2)$ & 57.4 & $(1.5)$ & 58.6 & $(1.5)$ & 57.4 & $(1.1$ & 62.3 \\
\hline & DW & 579.57 & $(0.18)$ & 580.70 & $(0.17)$ & 580.44 & $(0.23)$ & 580.07 & $(0.16)$ & 579.85 & $(0.16)$ & 579.26 & $(0.14)$ & 581.2 \\
\hline & $\mathrm{EP}$ & 0.265 & $5(0.006)$ & 0.225 & $(0.009)$ & 0.224 & $(0.010)$ & 0.226 & $6(0.011)$ & 0.236 & $5(0.012)$ & 0.278 & $3(0.024)$ & $0.180(0.017)$ \\
\hline & CR & 0.694 & $+(0.012)$ & 0.721 & $(0.025)$ & 0.720 & $(0.028)$ & 0.718 & $8(0.032)$ & 0.721 & $1(0.032)$ & 0.729 & $9(0.039)$ & $0.849(0.024)$ \\
\hline Hue $\mathrm{V}$ & ive/Chroma & $2.5 \mathrm{Y}$ & $7.5 / 3$ & $10 Y R$ & $7.5 / 2$ & $10 Y R$ & $7.5 / 2$ & $10 \mathrm{YP}$ & R $7.5 / 2$ & $10 Y^{\prime}$ & $7.5 / 2$ & $2.5 \mathrm{Y}$ & $7.5 / 4$ & $10 \mathrm{YR} \quad 8.0 / 2$ \\
\hline \multicolumn{15}{|l|}{$\mathrm{C}$} \\
\hline & $\mathrm{Y}$ & 66.1 & $(1.4)$ & 60.0 & $(1.5)$ & 59.7 & $(1.2)$ & 58.4 & $(1.1)$ & 57.9 & $(1.0)$ & 56.7 & $(0.3)$ & $(2.3)$ \\
\hline & DW & 578.53 & $(0.05)$ & 578.99 & $(0.13)$ & 578.92 & $(0.11)$ & 578.88 & $(0.04)$ & 578.97 & $(0.09)$ & 579.17 & $(0.24)$ & $581.10(1.68)$ \\
\hline & EP & 0.307 & $(0.007)$ & 0.309 & $(0.014)$ & 0.317 & $(0.014)$ & 0.33 & $7(0.016)$ & 0.350 & $(0.016)$ & 0.365 & $5(0.035)$ & $0.224(0.017)$ \\
\hline & CR & 0.658 & $3(0.013)$ & 0.698 & $3(0.029)$ & 0.702 & $(0.026)$ & 0.703 & $3(0.027)$ & 0.710 & $(0.025)$ & 0.725 & $5(0.038)$ & $0.840(0.028)$ \\
\hline Hue $V_{2}$ & Iue/Chroma & $2.5 \mathrm{Y}$ & $8.0 / 4$ & $2.5 \mathrm{Y}$ & $7.5 / 4$ & $2.5 Y$ & $7.5 / 4$ & $2.5 \mathrm{Y}$ & $7.5 / 4$ & $2.5 \mathrm{Y}$ & $7.5 / 4$ & $2.5 Y$ & $7.5 / 5$ & 10YR $8.0 / 3$ \\
\hline \multicolumn{15}{|l|}{$\mathrm{NF}$} \\
\hline & $Y$ & 78.9 & $(1.5)$ & 62.1 & $(0.7)$ & 63.7 & $(1.0)$ & 65.8 & $(1.1)$ & 70.4 & $(1.4)$ & 21.7 & $(1.6)$ & $(0.7)$ \\
\hline & DW & 576.11 & $(0.11)$ & 577.20 & 2) & 576.50 & 211 & 575.59 & & 575.34 & $(0.08)$ & 575.86 & $(0.06)$ & $576.47(0.14)$ \\
\hline & $\mathrm{EP}$ & 0.160 & $(0.001)$ & 0.334 & $(0.008)$ & 0.334 & $(0.006)$ & 0.33 & $3(0.007)$ & 0.310 & $(0.009)$ & 0.260 & $(0.015)$ & $0.179(0.013)$ \\
\hline & $\mathrm{CR}$ & $0.58 ?$ & $(0.010)$ & 0.638 & $3(0.020)$ & 0.635 & $(0.014)$ & 0.621 & $1(0.014)$ & 0.617 & $(0.012)$ & 0.615 & $(0.016)$ & $0.706(0.017)$ \\
\hline Hue $\mathrm{V}$ & lue/Chroma & $5.0 \mathrm{Y}$ & $8.5 / 2$ & $2.5 \mathrm{Y}$ & $3.5 / 4$ & $5.0 \mathrm{Y}$ & $8.0 / 4$ & $5.0 \mathrm{Y}$ & $8.0 / 4$ & $5.0 \mathrm{Y}$ & 8.014 & $5.0 \mathrm{Y}$ & $8.0 / 3$ & $5.0 Y \quad 8.5 / 2$ \\
\hline
\end{tabular}

* Obtained for a white background (condition b).

analysis of variance 10 to determine the effects of products and times for the composite resins, unfilled resin, and for the glazes. Data for the contrast ratio were studied by a one-way analysis of variance. ${ }^{10}$ Tukey's intervals at the 95 percent level of confidence were calculated 11 for comparisons among means. Comparisons among colors determined visually were made by use of an estimate of the critical color dif- ference ${ }^{7}\left(I_{C}\right)$ necessary to show a difference between two colors. $I_{c}$ was calculated at the 95 percent level of confidence.

\section{Results.}

Mean values and standard deviations of luminous reflectance $(\mathrm{Y})$, dominant wavelength (DW), excitation purity (EP), and

TABLE 3

SPECTROPHOTOMETRIC AND MUNSHLL COLOR DATA FOR COMPOSITE AND UNFILLED RESINS AT BASELINE AND AFTER AGING

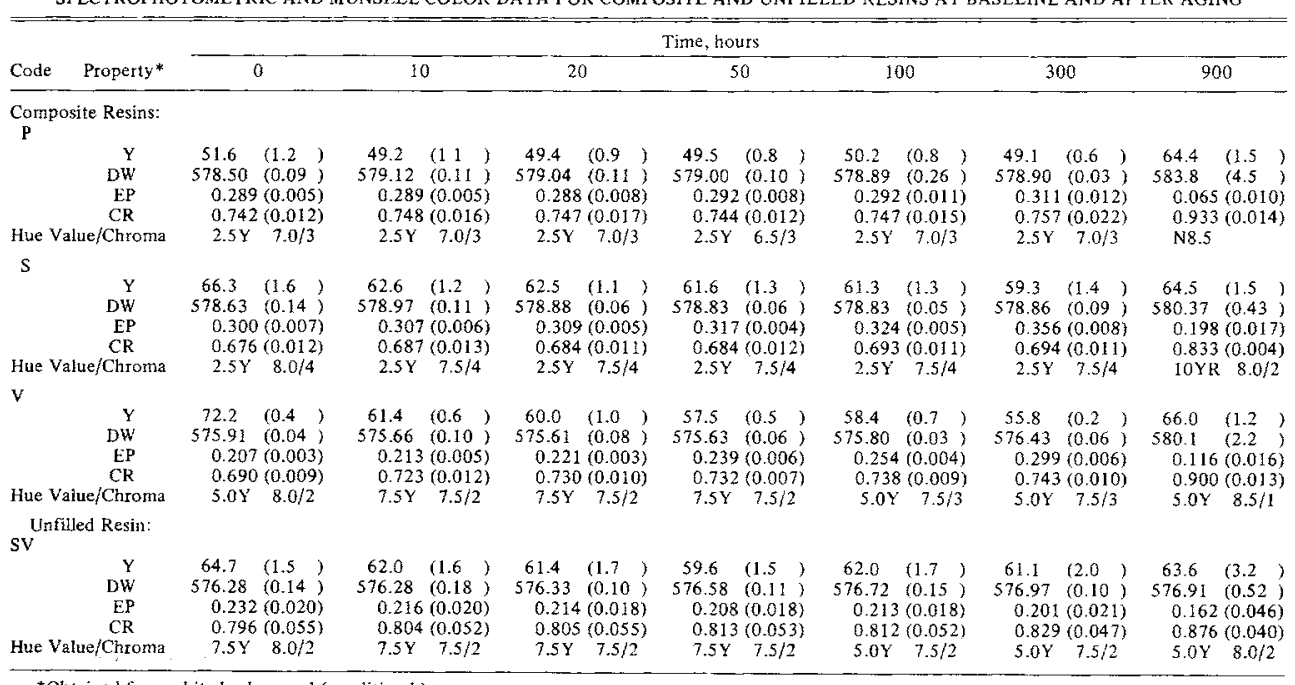

*Obtained for a white background (condition b). 
TABLE 4

SPECTROPHOTOMETRIC AND MUNSELL COLOR DATA FOR GLAZES AT BASELINE AND AFTER AGING

\begin{tabular}{|c|c|c|c|c|c|c|c|c|c|c|c|c|c|c|}
\hline \multirow{3}{*}{$\frac{\text { Code }}{F}$} & \multirow{3}{*}{ Property* } & \multicolumn{13}{|c|}{ Tine, hours } \\
\hline & & \multicolumn{2}{|c|}{0} & \multicolumn{2}{|c|}{10} & \multicolumn{2}{|c|}{20} & \multicolumn{2}{|c|}{50} & \multicolumn{2}{|c|}{100} & \multicolumn{2}{|c|}{300} & 900 \\
\hline & & & & & & & & & & & & & & \\
\hline & $Y$ & 67.9 & $(1.1)$ & 55.4 & $(0.9)$ & 55.4 & $(0.7)$ & 56.2 & $(0.7)$ & 57.2 & $(0.6)$ & 53.6 & $(0.8)$ & 43.3 \\
\hline & DW & 575.78 & $(0.19)$ & 577.73 & $(0.11)$ & 577.82 & $(0.12)$ & 577.89 & $(0.05)$ & 577.79 & $(0.08)$ & 578.47 & $(0.13)$ & $580.50 \quad(0.19$ \\
\hline & $\mathrm{EP}$ & 0.294 & $4(0.013)$ & 0.359 & $(0.006)$ & 0.365 & $5(0.004)$ & 0.393 & $(0.005)$ & 0.41 & $(0.007)$ & 0.474 & $(0.008)$ & $0.577(0.008)$ \\
\hline & CR & 0.317 & $7(0.010)$ & 0.325 & $(0.010)$ & 0.324 & $4(0.009)$ & 0.321 & $(0.007)$ & 0.33 & $(0.009)$ & 0.342 & $(0.010)$ & $0.424(0.018)$ \\
\hline \multicolumn{2}{|c|}{ Hue Value/Chroma } & $2.5 Y$ & $7.5 / 5$ & $2.5 \mathrm{Y}$ & $7.5 / 5$ & $2.5 Y$ & $7.0 / 5$ & $2.5 \mathrm{Y}$ & $7.5 / 6$ & $2.5 \mathrm{Y}$ & $7.5 / 6.5$ & $2.5 \mathrm{Y}$ & $7.0 / 7$ & $10 \mathrm{YR} \quad 6.017$ \\
\hline \multicolumn{15}{|l|}{$G$} \\
\hline & $\mathrm{Y}$ & 80.4 & $(0.7)$ & 77.5 & $(0.8)$ & 77.6 & $(0.6)$ & 78.2 & $(0.6)$ & 79.9 & $(0.5)$ & 78.4 & $(0.6)$ & $72.0 \quad(1.0$ \\
\hline & DW & 573.48 & $(0.26)$ & 574.53 & $(0.11)$ & 574.71 & $(0.12)$ & 574.62 & $(0.11)$ & 574.21 & $(0.12)$ & 574.29 & $(0.08)$ & $574.99 \quad 0.11$ \\
\hline & EP & 0.154 & $4(0.010)$ & 0.137 & $(0.010)$ & 0.133 & $3(0.004)$ & 0.130 & $(0.004)$ & 0.12 & $(0.005)$ & 0.157 & $(0.006)$ & $0.238(0.009)$ \\
\hline & CR & 0.116 & $6(0.006)$ & 0.107 & $(0.002)$ & 0.106 & $5(0.004)$ & 0.103 & $(0.004)$ & 0.10 & $(0.004)$ & 0.107 & $(0.001)$ & $0.109(0.004)$ \\
\hline Hue $V$ & tue/Chroma & $5.0 \mathrm{Y}$ & $9.0 / 3$ & $7.5 Y$ & $9.0 / 2$ & $7.5 Y$ & $9.0 / 2$ & $5.0 \mathrm{Y}$ & $9.0 / 2$ & $5.0 \mathrm{Y}$ & $9.0 / 2$ & $5.0 \mathrm{Y}$ & $9.0 / 2$ & $2.5 \mathrm{Y} \quad 8.5 / 3$ \\
\hline \multicolumn{15}{|l|}{ NS } \\
\hline & $\mathrm{Y}$ & 87.7 & $(1.0)$ & 82.8 & $(1.5)$ & 82.3 & $(1.6)$ & 80.6 & $(1.5)$ & 83.0 & $(0.9)$ & 81.4 & $(0.9)$ & $76.9 \quad(1.1$ \\
\hline & DW & 571.07 & $(0.14)$ & 571.09 & $(0.18)$ & 571.71 & $(0.13)$ & 572.61 & $(0.20)$ & 573.29 & $(0.88)$ & 573.49 & $(0.08)$ & $574.12 \quad(0.12$ \\
\hline & $\mathrm{EP}$ & 0.035 & $5(0.006)$ & 0.172 & $(0.035)$ & 0.136 & $6(0.033)$ & 0.115 & $(0.022)$ & 0.10 & $(0.016)$ & 0.134 & $(0.011)$ & $0.209(0.012)$ \\
\hline & CR & 0.102 & $2(0.004)$ & 0.105 & $5(0.004)$ & 0.102 & $2(0.004)$ & 0.102 & $2(0.009)$ & 0.10 & $(0.007)$ & 0.103 & $3(0.004)$ & $0.096(0.006)$ \\
\hline Hue $V$ & alue/Chroma & $10 \mathrm{Y}$ & $9.5 / 1$ & $10 Y$ & $9.0 / 4$ & $10 \mathrm{Y}$ & $9.0 / 3$ & $10 Y$ & $9.0 / 2$ & $7.5 \mathrm{Y}$ & $9.0 / 2$ & $7.5 \mathrm{Y}$ & 9.012 & $5.0 \times \quad 8.5 / 3$ \\
\hline
\end{tabular}

* Obtained for a white background (condition b).

contrast ratio (CR) are listed in Tables 2 and 3 for the composite resins and the unfilled resin, and in Table 4 for the glazes at baseline and after aging. Data obtained for a white standard are presented. The consensus values of Munsell color determined against a white background are also listed in Table 2 - 4.

Differences among materials and among times and their interaction were significant at the 95 percent level of confidence for the three spectrophotometric parameters, and the contrast ratio for the composite and unfilled resins. Analysis of variance for the glazes was made and similar results were found. Tukey's intervals at the 95 percent level for comparisons of means among products and among times are listed in Table 5 for the composite and unfilled resins and for the glazes.
Mean values of luminous reflectance (Y) versus time of aging are plotted in Figure 1 for five resins. The curve shown for $\mathrm{A}$ is representative of the behavior of $\mathrm{Ar}$, $C, S$, and SV. Among resins listed in Tables 2 and 3 the maximum change in $Y$ varied from 4.9 for AR to 9.4 for $C$. The behavior of NF, $P$, and $V$ was unique even though the maximum change in $\mathrm{Y}$ only varied from 15.3 to 16.8. After aging for 900 hours, five resins $(C, N F, S, S V$, and $V$ ) were darker, and three resins ( $A, A R$, and $P$ ) were lighter than at baseline. The luminous reflectance of the glazes decreased from zero to 900 hours, but the change in $\mathrm{Y}$ was more dramatic for $F$ than for NS or G.

Mean values of dominant wavelength for the resins and glazes increased after 900 hours of aging by 4.2 to $5.3 \mathrm{~nm}$ for $\mathrm{V}$, $\mathrm{F}$, and $\mathrm{P}$; from 2.6 to $3.0 \mathrm{~nm}$ for $\mathrm{C}$ and $\mathrm{NS}$;

TABLE 5

TUKEY'S INTERVALS FOR COMPARISONS AMONG MEAN VALUES OF SPECTROPHOTOMETRIC DATA

\begin{tabular}{|c|c|c|c|c|}
\hline \multirow[b]{2}{*}{ Comparisons } & \multicolumn{4}{|c|}{ Tukey's Intervals } \\
\hline & $\begin{array}{c}\text { Luminous } \\
\text { Reflectance }(\mathrm{Y})\end{array}$ & $\begin{array}{c}\text { Dominant } \\
\text { Wavelength, } \mathrm{nm}\end{array}$ & $\begin{array}{l}\text { Excitation } \\
\text { Purity }\end{array}$ & $\begin{array}{c}\text { Contrast } \\
\text { Ratio }\end{array}$ \\
\hline $\begin{array}{l}\text { Among composite } \\
\text { and unfilled resins }\end{array}$ & 0.9 & 0.11 & 0.010 & 0.021 \\
\hline $\begin{array}{l}\text { Among times for } \\
\text { composite and } \\
\text { unfilled resins }\end{array}$ & 0.8 & 0.09 & 0.008 & 0.017 \\
\hline Among glazes & 0.6 & 0.15 & 0.009 & 0.004 \\
\hline Among times for glazes & 1.0 & 0.26 & 0.016 & 0.007 \\
\hline
\end{tabular}




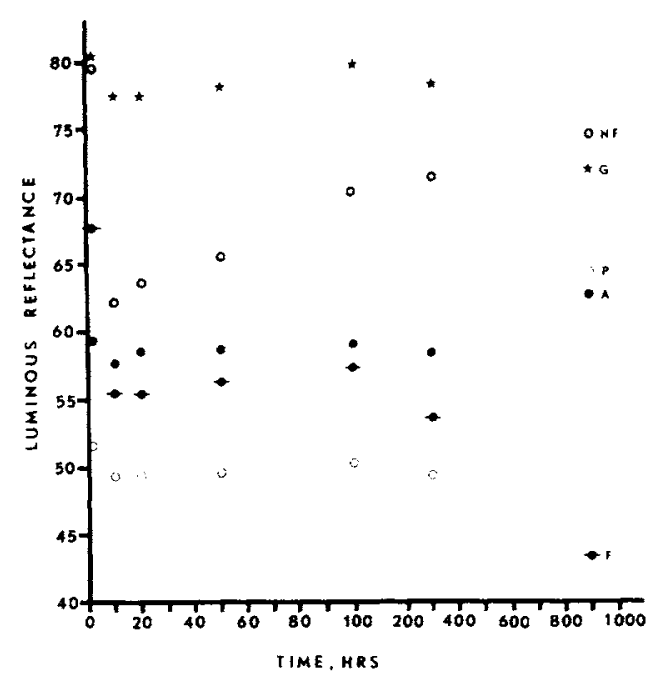

Fig. 1 - Luminous reflection of selected restorative resins versus time of aging. Note that the 900 hour data points also serve as the key.

from 1.5 to $1.7 \mathrm{~nm}$ for $\mathrm{G}, \mathrm{AR}$, and $\mathrm{S}$; and by less than $0.6 \mathrm{~nm}$ for $\mathrm{A}, \mathrm{NF}$, and $\mathrm{SV}$ as compared to baseline.

Mean values of excitation purity (EP) versus time of aging are plotted in Figure 2 for five resins. The curve shown for $A$ is representative of the behavior of $A R$ and $\mathrm{SV}$, whereas that for $\mathrm{P}$ is representative of $\mathrm{C}$, $S$ and $V$. The behavior of NF was unique. After aging for 900 hours, the change in EP was from -0.070 to -0.102 for $\mathrm{SV}, \mathrm{C}, \mathrm{AR}$, $A, V$, and $S$, respectively, -0.224 for $P$ and to.019 for NF. Among the glazes tested, the

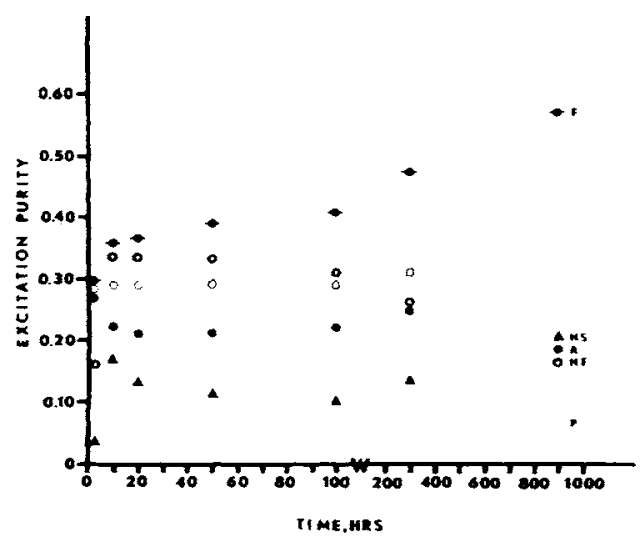

Fig. 2 - Excitation purity of selected restorative resins versus time of aging. Note that the 900 hour data points also serve as the key.

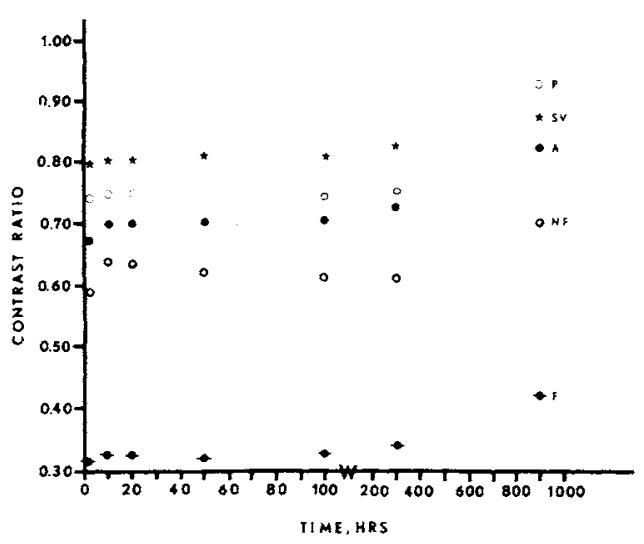

Fig. 3 - Contrast ratio of selected restorative resins versus time of aging. Note that the 900 hour data points also serve as the key.

behavior of $F$ was unique, whereas the curves of NS and G were similar from 10 to 900 hours.

Mean values of the contrast ratio (CR) versus time of aging are plotted in Figure 3 for five resins. The curve shown for A is representative of the behavior of $A R$ and $S$ for which CR increased by about 0.15 after 900 hours of aging. The curve shown for $P$ is representative of $\mathrm{C}$ and $\mathrm{V}$ for which $\mathrm{CR}$ increased by 0.18 for $\mathrm{C}$ to 0.21 for $\mathrm{V}$. The resins NF and SV showed increases of 0.12 and 0.08 , respectively, after 900 hours. Among the glazes, $F$ showed an increase of 0.11 , whereas both $\mathrm{G}$ and NS showed a decrease in CR of less than 0.01 after 900 hours.

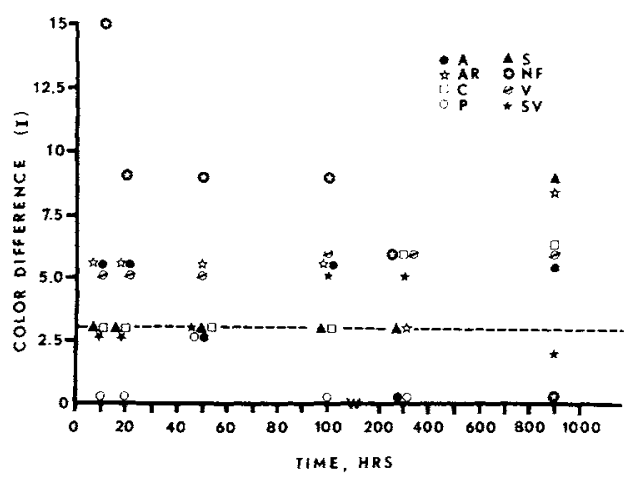

Fig. 4 - Color difference between baseline and aged samples for composite and unfilled resins. Dashed line indicates value of $I_{c}$. Value for $I$ of $P$ at 900 hours could not be calculated. 


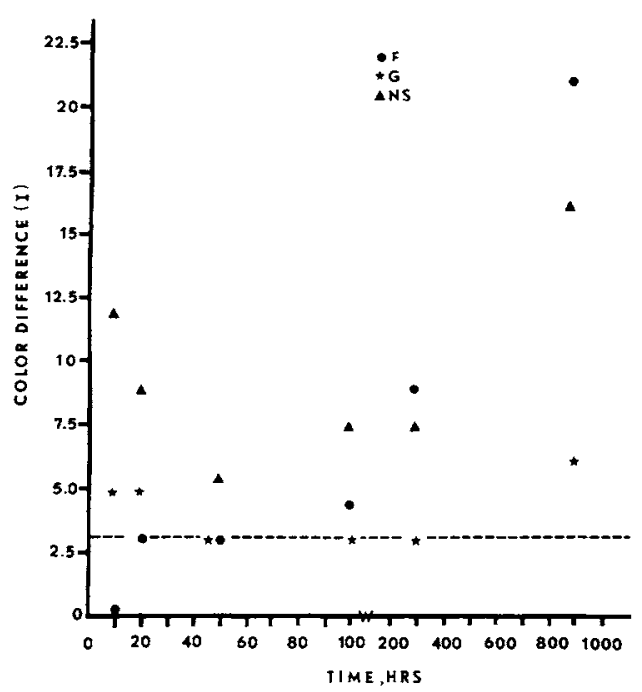

Fig. 5 - Color differences between baseline and aged samples for glazes. Dashed line indicates value of $\mathbf{I}_{c}$.

The color differences (I) between each time of aging and baseline determined from the concensus values of Munsell color are plotted in Figure 4 for the composite and unfilled resins, and in Figure 5 for the glazes. The critical color difference $\left(I_{c}\right)$ was 3.1 as indicated by a dashed line in each figure. After 10 hours of aging, significant changes in color were observed in four composite resins ( $\mathrm{A}, \mathrm{AR}, \mathrm{NF}$, and $\mathrm{V}$ ), and in glazes $G$ and NS. After 900 hours of aging, however, only two restorative resins (NF and SV) had values of I less than $I_{c}$. The value of $I$ for $P$ after 900 hours could not be calculated because $P$ was achromatic.

\section{Discussion.}

The xenon light source of the weathering instrument is a long arc, water-cooled type which has an energy distribution curve that approximates that of noon summer sunlight at Chicago, Illinois. 12 The borosilicate glass filter used with the light source has a low cutoff at $275 \mathrm{~nm}$ so that the radiant energy is very close to natural unfiltered sunlight. The manufacturer of the weathering instrument estimates that 300 hours of aging are equivalent to one year of clinical service.

The ability to predict long-term changes

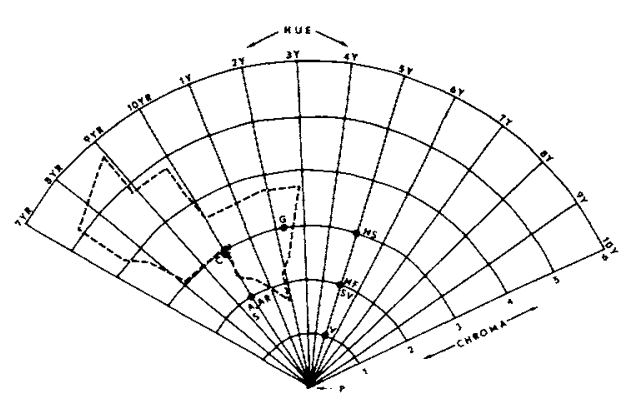

Fig. 6 - A comparison of the color distribution for hue and chroma between restorative resins after aging for 900 hours and human teeth. ${ }^{13} \mathrm{~F}$ is off scale with a hue of $10 Y R$ and a chroma of 7 .

in the color of restorative resins based on short-term accelerated aging is desirable, but may not be achievable. For aging up to 300 hours, the spectrophotometric parameters of the resins were more or less equal to values obtained after 10 hours of aging, except for F and NF. Between 300 and 900 hours of accelerated aging, however, dramatic changes in color occurred for most of the resins that would not have been anticipated from earlier behavior.

Among the resins tested at baseline, only $A, A R$, and $P$ were within the range for hue and chroma of human teeth, whereas $\mathrm{A}, \mathrm{AR}, \mathrm{P}, \mathrm{SV}$, and $\mathrm{V}$ were within the range for value and chroma of human teeth as reported previously. 7 After aging for 900 hours, only $G$ is within the range of hue and chroma for human teeth (see Figure 6) as reported by Sproull.13 A, AR, C, and S possess too little and $F$ too much chroma, whereas NF, NS, P, SV, and $V$ are outside the range for a natural hue. AR, S, and SV fall within the range for value and chroma of human teeth 13 after aging for 900 hours (see Figure 7). The materials C, G, NF, and NS after aging are too light in value for the amount of chroma displayed, whereas A, P, and $\mathrm{V}$ show insufficient chroma and $\mathrm{F}$ shows too much chroma compared to the range for human teeth. The failure of most resins to fall within the range of color for human teeth is exaggerated by the dramatic increase in opacity of the resins (except $G$ and NS) that would result in less effective transmission of the color of the supporting tooth in a clinical situation. 


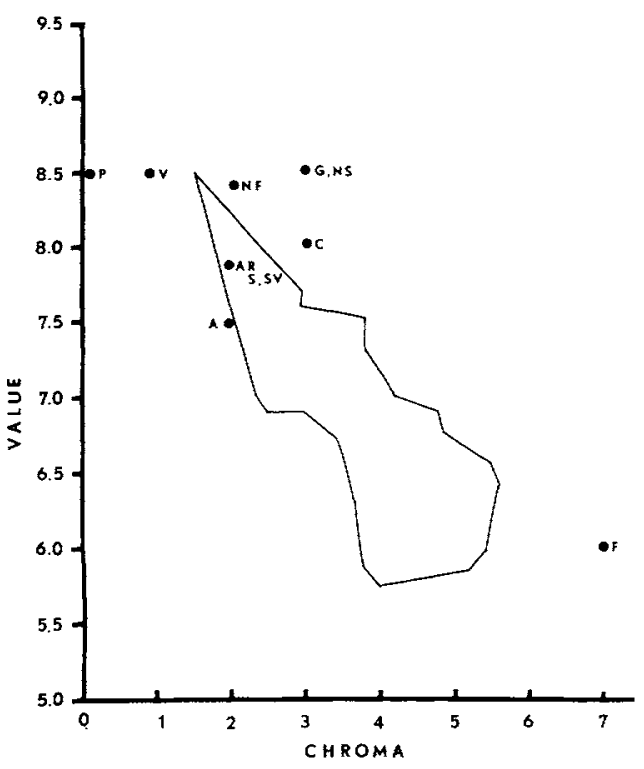

Fig. 7 - A comparison of the color distribution for value and chroma between restorative resins after aging for 900 hours and human teeth.13

\section{Conclusions.}

The color stability of seven commercial composite resins, an unfilled resin, and three glazes was studied under conditions of accelerated aging by reflection spectrophotometry and visually with Munsell color tabs. After aging for 900 hours, most of the resins had lower values of luminous reflectance and excitation purity and higher values of dominant wavelength and contrast ratio compared to values at baseline. After 10 hours of aging, significant visual changes in color were observed in four composite resins and in two glazes. After 900 hours, all but one composite and an unfilled resin showed visual changes in color that were different statistically from baseline. For some of the resins, changes in color that were observed at 900 hours could not have been predicted from data obtained over a shorter period of aging.

\section{REFERENCES}

1. LEINFELDER, K. F.; SLUDER, T. B.; SOCKWELL, C. L.;STRICKLAND, W. D. ; and WALL, J. T.: Clinical Evaluation of Composite Resins as Anterior and Posterior Restorative Materials, J. Prosthet. Dent. $33: 407-416,1975$.

2. LIATUKAS, E. L.: A Clinical Investigation of Composite Resin Restorations in Anterior Teeth, J. Prosthet. Dent. 27:616-621, 1972.

3. FUSAYAMA, T.; HIRANO, T.; and KONO, A.: Discoloration Test of Acrylic Resin Fillings by an Organic Dye, $J$. Prosthet. Dent. 25:532-539, 1971.

4. PETERSON, E. A.; PHILlIPS, R. W.; and SWARTZ, M. L.: A Comparison of the Physical Properties of Four Restorative Resins, JADA 73:1324-1336, 1966.

5. LEE, H. L.;ORLOWSKI, J. A.; and ROGERS, B. J.: A Comparison of Ultraviolet-curing and Self-curing Polymers in Preventive, Restorative, and Orthodontic Dentistry, Internat. Dent. J. 26:134-151, 1976.

6. American Dental Association, Council on Dental Materials and Devices: Specification No. 27 for Direct Filing Resins, JADA 94: 1191-1194, 1977

7. DENNISON, J. B.; POWERS, J. M.; and KORAN, A.: Color of Dental Restorative Resins, J. Dent. Res. 57:557-562, 1978.

8. NICKERSON, D.: The Specification of Color Tolerances, Textile Research 6:509, 1936.

9. Opacity of paper, D589-65 (1970): (in ASTM Standards, 1975, part 20. Philadelphia, American Society for Testing and Materials, 1975, p. 86-88).

10. DALBY, JOHN, Programmer: BMD8VAnalysis of Variance, Ann Arbor, Statistical Research Laboratory, University of Michigan, 1968.

11. GUENTHER, W. C.: Analysis of Variance, Englewood Cliffs, NJ, Prentice-Hall, 1964, $199 \mathrm{p}$.

12. Atlas Electric Devices Co.: Instructions 25 WR-T, Chicago, Atlas Electric Devices Co., $39 \mathrm{p}$.

13. SPROULL, R. C.: Color Matching in Dentistry, Part II. Practical Applications of the Organization of Color, J. Prosthet. Dent. 29:556-566, 1973. 